\title{
ARE THERE ANY ECONOMIC IMPACTS OF BUSINESS R\&D SUPPORT? THE CASE OF THE CZECH REPUBLIC
}

\section{Ratinger, T., Čadil, V., Agyemang Amaoko, S.}

Tomáš Ratinger, Vladislav Čadil / Technology Centre, Czech Academy of Sciences, Ve Struhách 27, 16000 Prague 6, Czech Republic.Email: ratinger@tc.cz, cadil@tc.cz.

Sylvester Amoako Agyemang / Czech University of Life Sciences Prague, Kamýcká 129, 16500 Prague 6-Suchdol, Czech Republic. Email: amoakoagyemangs@gmail.com.

\begin{abstract}
Evaluation of the economic impact of public research and development (R\&D) support has become an integral part of the policymaking process. The paper examines the economic effects of the Czech programme TIP supporting R\&D in private companies in the recent decade and aspires to contribute to the debate on quantitative methods for assessing outputs additionality of public R\&D programmes. The analysis is based on the counter-factual econometric approach, because an appropriate control group could not be found among the unsupported companies, a so-called generalized propensity score matching (GPSM) was used. Two data sources were used: monitoring data of the programme TIP and economic data from the database Bisnode-MagnusWeb. The impact of R\&D support on the firms' performance was measured by output indicators: gross value added, profit and productivity. Treatment effects are diverse depending on firm sizes. Generally, the R\&D support effects are positive and more substantial in small and medium firms (SMEs) while there are no such effects confirmed for large firms. The support could only impact positively on the output (profit, productivity and gross value added) of small firms only after reaching a certain minimum threshold of the support whereas output diminishes for medium firms after a point of saturation.

Implications for Central European audience: This paper results could be useful for policymakers and R\&D funding providers because it provides evidence about the microeconomic impacts of programmes, namely it shows the differentiated effects of public interventions toby the size categories of beneficiaries. The analysis confirms that GPSM approach provides deliver logical outcomes and if the investigation is situated to the right period after the programme is accomplished, it has a potential to bring more insight in the effects than the standard dichotomous model.
\end{abstract}

Keywords: R\&D support; economic impacts; econometric approaches; generalized propensity score matching

JEL Classification: C01, C31 


\section{Introduction}

Evaluation of the economic impact of government support for business R\&D is a key theme in research and innovation policies evaluations and policy debates (Cunningham et al., 2016; Zúñiga-Vicente et al., 2014). Especially in these debates and evaluations, the issue of efficiency and effectiveness of the public support has been gaining increasing importance in recent years in the context of limited public resources on the one hand and the need to increase competitiveness on the other hand.

Several quantitative and qualitative methods can be used for the evaluation of economic impact (e.g. Cunningham et al., 2016). Among these methods, the counter-factual econometric analysis is becoming increasingly popular. Bondonio et al. (2016) used Conditional Difference in Difference (CDD) model implemented within a multiple regression framework to investigate the impact of innovation, investment and R\&D policies on the performance (employment, sales, GVA and labour productivity) of businesses in seven EU countries. Sidorkin and Srholec (2017) used propensity score matching (PSM) for evaluation of additional R\&D output in terms of applications for formal intellectual property (IP) protection in the Czech Republic.

The use of methods based on the comparison between strictly separated treated and control groups face some obstacles in terms of data availability and quality, interpretation and presentation of results to a non-specialist audience (Cunningham et al., 2017). A particular challenge is finding the right control group (Khandker et al., 2010), particularly if the country or investigated region is small and support measures plentiful (Bia \& Mattei, 2012).

This is also the case of evaluation of the economic impact of R\&D programmes in the Czech Republic, where the number of firms carrying out in-house R\&D is almost identical with the number of private companies receiving direct R\&D support. In simple terms, it can be said that each firm with their own R\&D activities has recently received direct R\&D subsidies. Moreover, many companies (particularly those which have a central position within their industries) have received support for a long time. From these reasons, it is almost impossible to find a suitable control group consisting of unsupported firms and to use common matchmaking techniques like PSM or Direct Covariate Matching (DCM).

If an appropriate control group cannot be found among the unsupported companies, a socalled generalized propensity score matching (GPSM) can be used, provided that firms receive a different level of treatment (support). The control group is created from the closest similar firms, which received a different level of support (Bia \& Mattei, 2012).

The objective of this paper is to examine the economic effects of the Czech programme TIP supporting $R \& D$ in private companies in the recent decade. Besides the evaluation of that particular programme, the paper aspires to contribute to debates on (i.) effectiveness of public policies launched in this journal by Špička (2018), and (ii.) quantitative methods for assessing outputs additionality of the public funds poured in the sectors (Athey \& Imbens, 2017) and the suitability and usefulness of GPSM for impact evaluation in general. This paper is an extension of our earlier conference paper (see Ratinger et al., 2019) that was presented at the Innovation, Management, Entrepreneurship and Sustainability Conference, which took place on May 29-31, 2019 at the University of Economics, Prague. Unlike the conference paper, this article places the topic in a broader framework of the business R\&D support evaluation and presents the final results of the econometric analysis. 
The TIP programme was implemented by the Ministry of Industry and Trade from 2009 through 2016 with the total financial allocation of CZK 12.5 billion (EUR 480 million). It aimed to provide grants supporting applied research and development projects in the fields of new materials, new progressive technologies and new information and control systems. In four calls the programme supported 707 subjects, of which 626 were private companies (approx. $90 \%$ of supported subjects) receiving more than CZK 8.8 billion (EUR 335 million). Evaluation of the TIP programme (Čadil et al., 2018) showed that the main motive for the participation in the TIP programme was to increase competitiveness in foreign and domestic markets together with to achieve or maintain a leading position in the market. The projects were based on long-term strategic research activities of supported companies targeting further technological development and gaining a new market niche. The highest number of participants operated in R\&D industries - Architectural and engineering activities, technical testing and analysis (NACE 71); Research and Development (NACE 72) and manufacturing industries - Manufacture of machinery and equipment (NACE 28), Manufacture of computers, electronic and optical products (NACE 26) and Manufacture of electrical equipment (NACE 27).

The paper is structured as follows. Except for the introductory chapter and conclusions, the paper is divided into three distinct sections. The first section gives a brief review of recent literature findings. The next part describes the GPSM approach as a conceptual framework of this paper. Finally, the third section analyses and discusses the results.

\section{Literature review}

Over the past few decades, national and regional governments have been providing direct support to the development of R\&D capacities and capabilities of private firms for many reasons. The most important reasons include public goods characteristic of knowledge creation, market failures caused by high risk and uncertainty in $R \& D$, competitiveness strengthening in international markets or knowledge diffusion and R\&D cooperation stimulation (Bozeman and Deitz, 2001; Cunningham et al., 2016).

The government interventions are intended to generate positive effects on beneficiaries in terms of increasing innovation activities and economic development. Nevertheless, based on the systematic examination of 24 empirical studies and articles analysing output additionality in EU and other OECD countries Cunningham et al. (2016) found that the government support had ambiguous impacts on economic and innovation performance of the firms. Similarly, What Works Centre for Local Economic Growth (2015) in a critical review of 36 empirical studies reports mixed findings. They found that state intervention may stimulate innovation and productivity growth but not always. The effects differ across the different types of innovations. This view is supported by Petrin (2018), who, in a review of 98 articles and evaluation studies from 1960-2017, confirms a great heterogeneity of results given by a wide range of empirical estimation approaches, and variety of definitions of outcomes and used indicators. She demonstrates that the effects of the government support on innovation and economic performance indicators such as numbers of patents, sales of new products and implementation of new processes depend on the definition of the measured indicators, the approaches and methods used as well as the period after which the interventions are evaluated. 
Together, these studies indicate that apart from evaluation methods and indicators used, the effects depend both on the characteristics of the enterprises (including size categories) and the focus of support programs. As regards to aims and targeting of the programs, Testa et al. (2019) argue that targeted funding focused on specific technologies leads towards better results for disruptive innovations, while generic $R \& D$ grants contribute more to the knowledge diffusion, since their results are rather new-to-the-firm rather than new-to-the-market. However, Petrin (2018) found that the effects of targeted support are slightly worse than generic (sector neutral) programs in terms of innovation.

As for the firm characteristics, the effects are most often analysed by the size structure of companies. Testa et al. (2019) mention that specific size groups of companies have different R\&D strategies resulting in various innovation and economic effects. For instance, large enterprises carried out intensive in-house $R \& D$, which can be characterized by large $R \& D$ facilities, immense internal expertise and knowledge stock, whilst R\&D carried out by small and medium companies depend more on collaboration and external knowledge sources. Therefore, large companies' firm may invest more in productivity-oriented R\&D thereby achieving higher productivity. In such instances, R\&D support might have a more positive effect on the productivity of large firms relative to small firms (Stam \& Wennberg, 2009; Raymond \& St-Pierre, 2010). However, Pavitt et al. (1987), Acs and Audretsch (1988), and Rothwell and Dodgson (1994) argue that innovative output per unit of public R\&D investment is higher for SMEs with public R\&D funding than large firms. Moreover, Audretsch and Vivarelli (1996) found that R\&D spillovers are more beneficial to innovative outputs of Italian small firms than large companies. In contrast to these discussions, Herrera and SanchezGonzalez (2013) state that public R\&D funding improves sales regardless of the firm size, and the effects depend more on strategies and specific markets of specific firms' size groups. They revealed that R\&D support provided to SMEs, in general, impacted more on sales of new-to-the-firm products, whereas the support of large firms rather increased sales of newto-the-market products.

Most of the current literature pays particular attention to the effects on innovation and the economic development of SMEs. Although some studies report mixed (Karhunen \& Huovari, 2015; Hong et al., 2015; Radicic et al.; 2016, Becker, 2015) or rather negative (Czarnitzki \& Delanote, 2015) results, the literature rather shows positive (or slightly positive) effects of the R\&D support (Huergo \& Moreno Martín, 2017; Bronzini \& Piselli, 2014; Radicic \& Pugh, 2015; Autio \& Rannikko, 2016; Grilli \& Murtinu, 2012). However, since SMEs are a very heterogeneous group of firms in terms of their size, age, technology, industry region or strategy, similarly heterogeneous are the subsidy effects on economic performance (Dvouletý et al., 2019).

Although the Czech Republic traditionally supports business R\&D, there has been little concern about the effect of $R \& D$ subsidies on innovation and economic performance of beneficiaries, as well as the sectors. So far, this issue has been studied by only a few researchers. In an analysis of the relationships between growth, innovation and subsidies in the period 2004-2007, Zemplinerová and Hromádková (2012) found that bigger firms are less efficient in transforming the innovation input into an output. Sidorkin and Srholec (2017) investigated the relation between $R \& D$ subsidies and intellectual property protection and revealed that the subsidies did not generate $R \& D$ outputs that were sufficiently novel to be protected abroad. A recent study by Horák and Květoň (2019) focused on regional and 
sectoral impacts of $R \& D$ subsidies showed that the support was more beneficial for firms located in regions with lower $R \& D$ intensity, while the differences in effects between supported and unsupported companies were very small.

The evidence reviewed here seems to suggest that the economic effects of R\&D subsidies will depend on the size of companies supported, the indicators of economic performance, and will be influenced by the relatively short time after the program completion. We can expect that the TIP program impacted more on SMEs than on large firms.

\section{Conceptual framework (GPSM) and data}

As pointed out above, most firms carrying out $R \& D$ activities receive public support. It is also evident that the amount of support considerably varies among firms, not only due to their size. Thus, we have a continuous distribution of public subsidies rather than a dichotomy between supported and unsupported firms. For this reason, we adopted a generalization of the propensity score model of Rosenbaum and Rubin (1983) for continuous treatment as proposed by Hirano and Imbens (2004).

We assume that probability to receive a lower or higher support depends on a set of covariates and that this dependence can be captured by a normal linear model.

$$
\left(\mathrm{t} \mid \mathrm{X}_{\mathrm{i}}\right) \approx \mathrm{N}\left(\beta_{0}+\beta_{1}{ }^{1 *} X_{i}, \sigma^{2}\right),
$$

where t refers to a treatment variable and $X$ to a vector of covariates, $\beta$ are coefficients of the linear model and $\sigma 2$ the variance.

The model to determine generalized propensity scores (GPS) is rather straightforward in terms of estimation (similar to the discrete case), however, it is worthy to stress that the levels of the treatment need to be checked for balancing property (see Bia \& Mattei, 2012). In the next step, the conditional expectation of the outcome (programme effect) is calculated as a function of the treatment level and GPS. In the third step, the dose-response function is estimated by averaging the estimated conditional expectation over the GPS at each level of the treatment we are interested in. Bia and Mattei (2012) implemented this approach in STATA, thus these steps are directly computed by the procedure called dose-response. The resulting Dose-Response Function indicates the estimated impact of a given level of the R\&D support on the outcome indicator. In this way it answers the counterfactual question, what would have happened to a given firm had if it received a different level of treatment. The (Marginal) Treatment Effect Function shows the change of the outcome indicators in response to a change of the treatment level.

In the analysis, we use data of two sources: monitoring data of the support programme TIP from the R\&D\&I Information System, and economic data from the database BisnodeMagnusWeb (DBMW). DBMW provides selected indicators of the financial reports of Czech companies (from the balance sheets and profit-loss accounts). The running period of the programme TIP was 2009 to 2016 and thus monitoring data of this period were completed by economic and financial indicators from DBMW. We added the economic data also for the year 2008 as a base year before the investigated programme was launched.

Thus, the analysis covered the period of 2009-2015 using the period of 2013-2015 for the impact's evaluation. Later years were not taken into consideration due to the lack of data for 
the majority of analysed companies. However, the data unavailability for all the years of the evaluated period reduced the number of analysed firms to 375 (i.e. $59.9 \%$ of supported firms).

We selected four indicators to measure programme effects: revenue, gross value added (GVA), labour productivity (represented by the ration GVA/labour_cost) and return on capital (given by the ratio net_operational_surplus/capital costs, where capital costs refer to the sum of depreciation, and paid rents and interests). We adopted difference in differences (D-I-D) approach which in turn means that instead with levels we worked with changes to the base year.

To fulfil the conditional independence assumption, which requires the outcome variable to be independent of the level of treatment conditional on the propensity score, covariates that simultaneously influence participation decision and the outcome variables were used as controls. In total 10 pre-treatment covariates were used - cash flow, fixed assets, current assets, equity, profit, long term debt/total assets, bank credit/total assets, intermediate consumption, depreciation, interest received by a firm.

Following Bia and Mattei (2012), we split the sample by size of beneficiaries assuming a different behaviour of large, medium and small size companies; for the latter, we carried out the logarithmic transformation of the treatment (funding) variable. The number of firms in these categories in the analysed sample compared to the total number of firms is shown in Table 1. A comparison of the sample with the total numbers of supported firms in the size categories demonstrates that the sample of analysed firms appropriately represents the characteristics of the original set of supported companies.

Table 1 | Size structure of supported firms and the sample - number of firms and R\&D support received

\begin{tabular}{|c|c|c|c|c|c|}
\hline & \multicolumn{5}{|c|}{ Number of firms } \\
\hline Size category & Total & $\%$ & Sample & $\%$ & $\begin{array}{l}\% \text { of firms in the } \\
\text { sample }\end{array}$ \\
\hline Small & 391 & 62.5 & 254 & 67.7 & 65.0 \\
\hline Medium & 145 & 23.1 & 65 & 17.3 & 44.8 \\
\hline Large & 90 & 14.4 & 56 & 15.0 & 62.2 \\
\hline \multirow[t]{3}{*}{ Total } & 626 & 100.0 & 375 & 100.0 & 59.9 \\
\hline & \multicolumn{5}{|c|}{ R\&D support received } \\
\hline & $\begin{array}{ll}\text { Total } & \text { (billion } \\
\text { CZK) } & \end{array}$ & $\%$ & $\begin{array}{l}\text { Sample (billion } \\
\text { CZK) }\end{array}$ & $\%$ & $\begin{array}{l}\% \text { of support in } \\
\text { the sample }\end{array}$ \\
\hline Small & 4.487 & 50.9 & 3.060 & 57.3 & 68.2 \\
\hline Medium & 2.821 & 32.0 & 1.309 & 24.5 & 46.4 \\
\hline Large & 1.513 & 17.1 & 0.970 & 18.2 & 64.1 \\
\hline Total & 8.821 & 100.0 & 5.339 & 100.0 & 60.5 \\
\hline
\end{tabular}

Source: R\&D\&I Information System, own calculation

\section{Results}

Table 2 shows the descriptive statistics of the treatment variable and the selected output variables categorized into groups of small, medium, large and the total sampled firms. The results show clear differences in received treatment (support) in the size categories of the firms. Whereas average support received by small firms falls well below the average support for sampled firms, the average support received by medium firms was close to the sample average; the large firms received on average twice as much than the average support in the 
sampled. Small firms exhibited very poor results in terms of profit and value-added, with negative averages, while medium and large firms were profitable on average. In contrast to absolute figures which suggest that the largest firm perform the best, in relative terms the medium size and small firms show better average results: medium-size firms had the highest (3937.90) average return on capital the small firms showed the best average labour productivity (lab_product $=1.14$ ).

From the descriptive statistics, we can well understand the differences between size groups as well as the fact that here called small firms are still pretty large rather fitting with the standard classification of medium-size firms, mediums size firms are already rather large firms and the large firms are extremely large companies. The other note which is worth to make is the fact that standard deviations are very big suggesting high heterogeneity of the firms in the size groups. We will comment on it later in the interpretation of the results and in the conclusion.

Table 2 | Descriptive statistics of the key variables (CZK thousands)

\begin{tabular}{lllll}
\hline Variable & Small Firms & Medium Firms & Large Firms & Sampled Firms \\
\cline { 2 - 5 } & $\begin{array}{l}\text { Mean } \\
\text { (Std. Dev.) }\end{array}$ & $\begin{array}{l}\text { Mean } \\
\text { (Std. Dev.) }\end{array}$ & $\begin{array}{l}\text { Mean } \\
\text { (Std. Dev.) }\end{array}$ & $\begin{array}{l}\text { Mean } \\
\text { (Std. Dev.) }\end{array}$ \\
\hline $\begin{array}{l}\text { R\&D support } \\
\text { received }\end{array}$ & 1492.84 & 2471.08 & 4002.30 & 2037.15 \\
(treatment) & $(2186.81)$ & $(3069.41)$ & $(9135.07)$ & $(4234.54)$ \\
revenue & 63923.14 & 444992.10 & 4881262.00 & 16998.81 \\
& $(66914.68)$ & $(145525.50)$ & $(9150282.00)$ & $(4526559.00)$ \\
profit & -9280.97 & 6427.01 & 167712.20 & 19872.73 \\
& $(164209.20)$ & $(57640.10)$ & $(670928.40)$ & $(298141.60)$ \\
gross & -13739.52 & 24515.21 & 452799.40 & 62561.12 \\
added & $(169474.80)$ & $(76207.15)$ & $(1683994.00)$ & $(681517.00)$ \\
return on & 1023.65 & 3937.90 & 21271.02 & 4621.12 \\
capital & $(2990.68)$ & $(9019.24)$ & $(28970.78)$ & $(13953.16)$ \\
labour & 1.14 & 0.77 & 1.00 & 1.04 \\
productivity & $(11.10)$ & $(2.78)$ & $(2.70)$ & $(9.17)$ \\
\hline
\end{tabular}

Source: own calculation

To estimate the impact of the R\&D support on the firms, a standard linear regression analysis (OLS) was adopted. Following the same GPS procedure discussed above, we estimated the conditional distribution of the treatment (R\&D support) given the covariates using OLS for the three classified firm sizes.

The normality of the disturbances was tested by Kolmogorov-Smirnov equality-ofdistributions test. The result proved that the assumption of normality was statistically satisfied at 0.05 alpha level for all models.

With the estimated GPS in hand, the test for the balancing property of the propensity score was carried out. Thus, testing that the conditional means of the pre-treatment variables given the GPS is not different between units belonging to a specific treatment interval and units belonging to other treatment intervals. We divided the treatment into three different intervals: small-scale $\leq 450 ; 451-1300$; >1300, medium-scale $\leq 600 ; 601-1800$; >1800 and largescale $\leq 1000 ; 1001-2500 ;>2500$. 
Using the t-test for the difference of means, only a few differences among treatment groups after balancing on the GPS were found for the three classified firms' categories. Albeit, the balancing property was not unanimous among various categories of the classified firms. The balancing property was therefore satisfied at $0.01,0.05$ and 0.10 alpha levels for different firms' categories.

After verification of the normality and balancing properties of the GPS, we run a regression with the conditional distribution of R\&D support given the pre-treatment variables (regressors) and an outcome variable (regressands). According to Hirano and Imbens (2004), the estimates of the regression have no direct interpretation but are used for the computation of the dose-response function.

The dose-response functions were estimated for each of the outcome variables for all the size classes of firms. The predicted level of outcomes (Profit, GVA and labour productivity at every level of R\&D support, given the pre-treatment variables for the three size classes of firms are shown in Figures 1 to 3 . The middle line in the individual charts represents the estimates of the dose-response function or treatment effect function whereas the upper and lower lines represent the bounds of the $95 \%$ confidence interval generated by bootstrapping with 100 replications.

The patterns of the dose-response and treatment effect functions are similar for GVA and Profit (in each size category) (see Figure 1 and Figure 2, resp.). The figures also show that the effects of the R\&D support differ by size groups for these two indicators. For a readier understanding we summarized patterns if the effects of R\&D support on GVA and profit in Table 3. It is vital to remind the reader that the dose-response function captures the total effect of the support while the treatment effect function represents the marginal effect of the support (if the support shifts to higher or lower level). For small firms, the dose-response and treatment effect functions are convex. It means that the effects are low or even negative up to some level of the R\&D support received. For the average effects, the threshold is about CZK 13 million, for the marginal effect, it is CZK 5 million (per investigated support period). Contrary to small companies, GVA and profit exhibit a concave shape of the dose-response function for medium-size firms. The total GVA effects are positive for all treatment/support levels while the profit effects turn negative when support exceeds CZK 10 million. More interesting are declining marginal effects of support on GVA and profit (we provide interpretation later). Concerning the large companies, there is no evidence of effects on GVA and profit at all. 
Table 3 | Review of effect of the R\&D support on GVA and profit by size classes

\begin{tabular}{l|l|l|l}
\hline Size group & Function & Shape & Interpretation \\
\hline Small & Dose-response & Concave & $\begin{array}{l}\text { Positive effects when supports } \\
\text { bigger than 13 mil. CZK } \\
\text { Increasing marginal effects when } \\
\text { supports bigger than 5 mil. CZK } \\
\text { Positive effects, increasing up to 10 } \\
\text { million CZK, then declining with the } \\
\text { support. } \\
\text { Declining marginal effect of the } \\
\text { supports } \\
\text { No effect }\end{array}$ \\
$\begin{array}{l}\text { Large } \\
(\mathrm{N}=56 \text { firms })\end{array}$ & Treatment effect & Dose-response & Convex \\
\hline
\end{tabular}

Note: the support figures are per the investigated support period. $\mathrm{N}=$ number of observations

Source: own interpretation

\section{Figure 1 | Dose-response functions of GVA}

\section{Small firms}

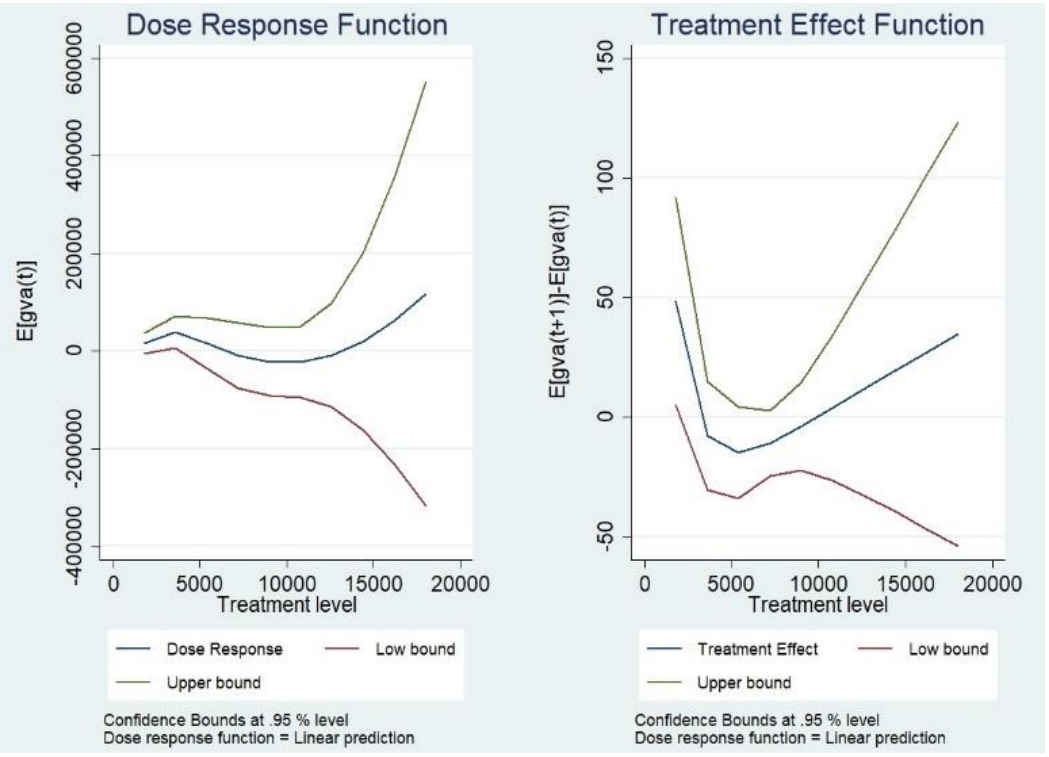




\section{Medium firms}

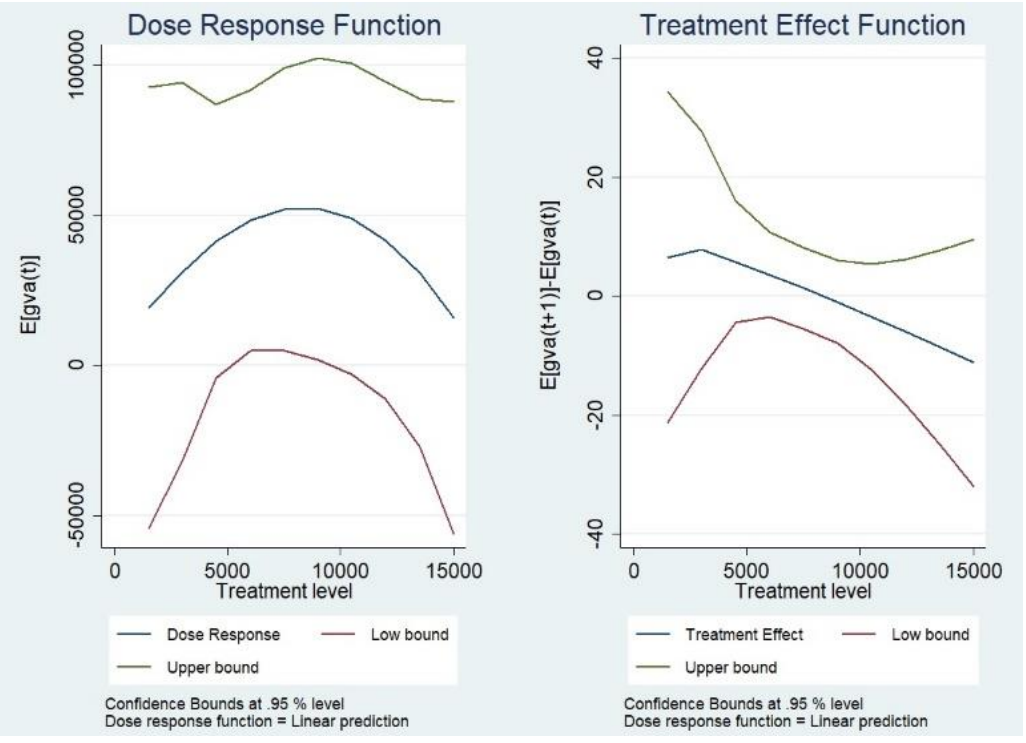

Source: author's elaboration

\section{Large firms}

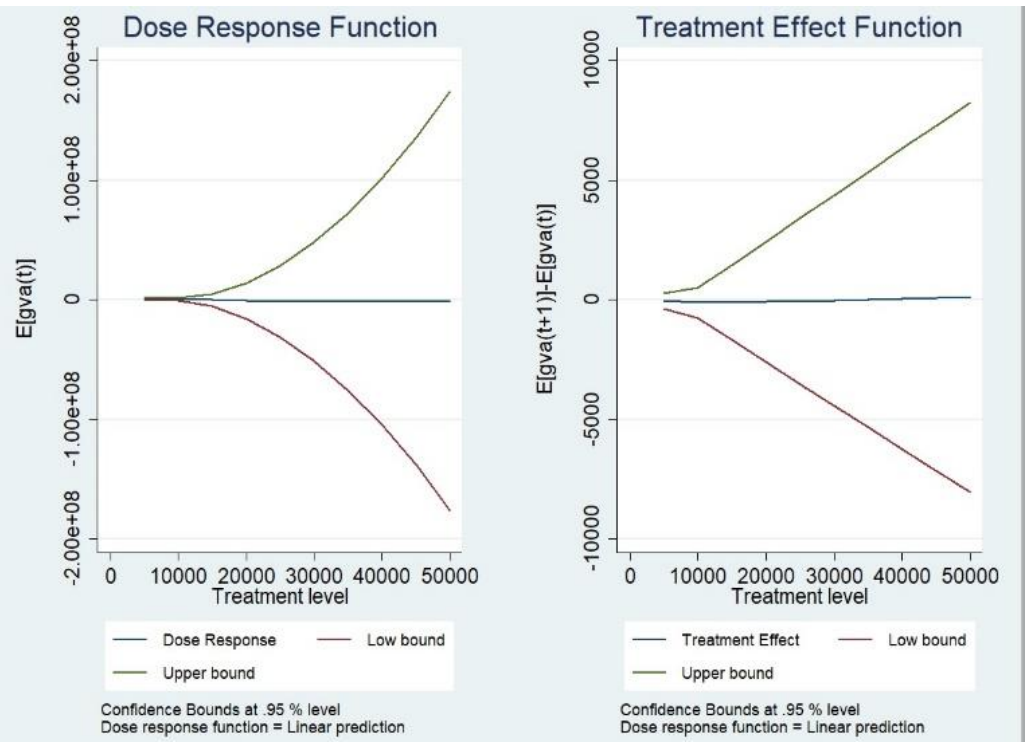

Source: author's elaboration 
Figure 2 | Dose-response functions of profit

\section{Small firms}

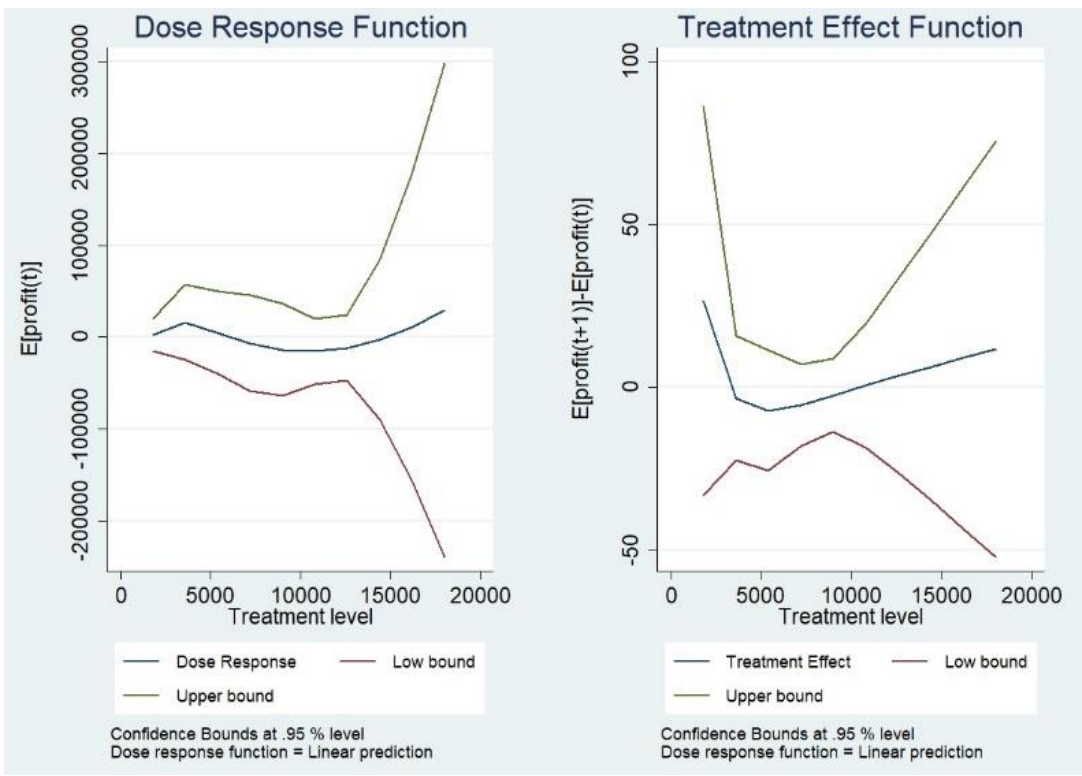

Source: author's elaboration

\section{Medium firms}

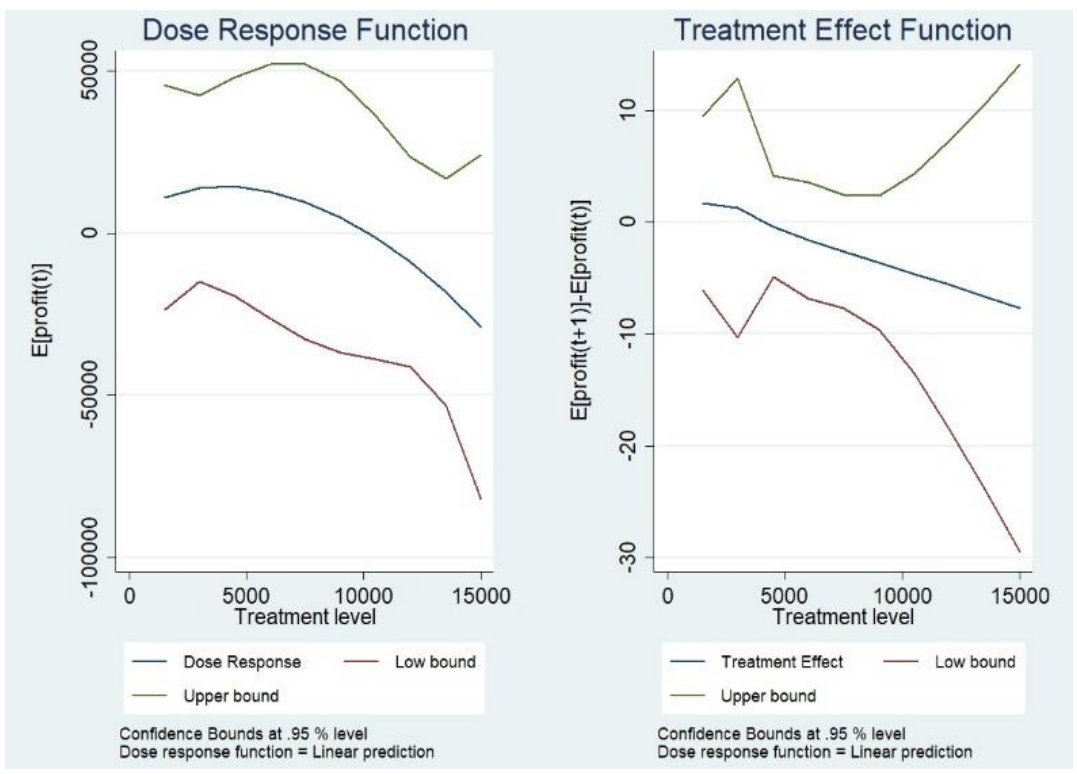

Source: author's elaboration 


\section{Large firms}

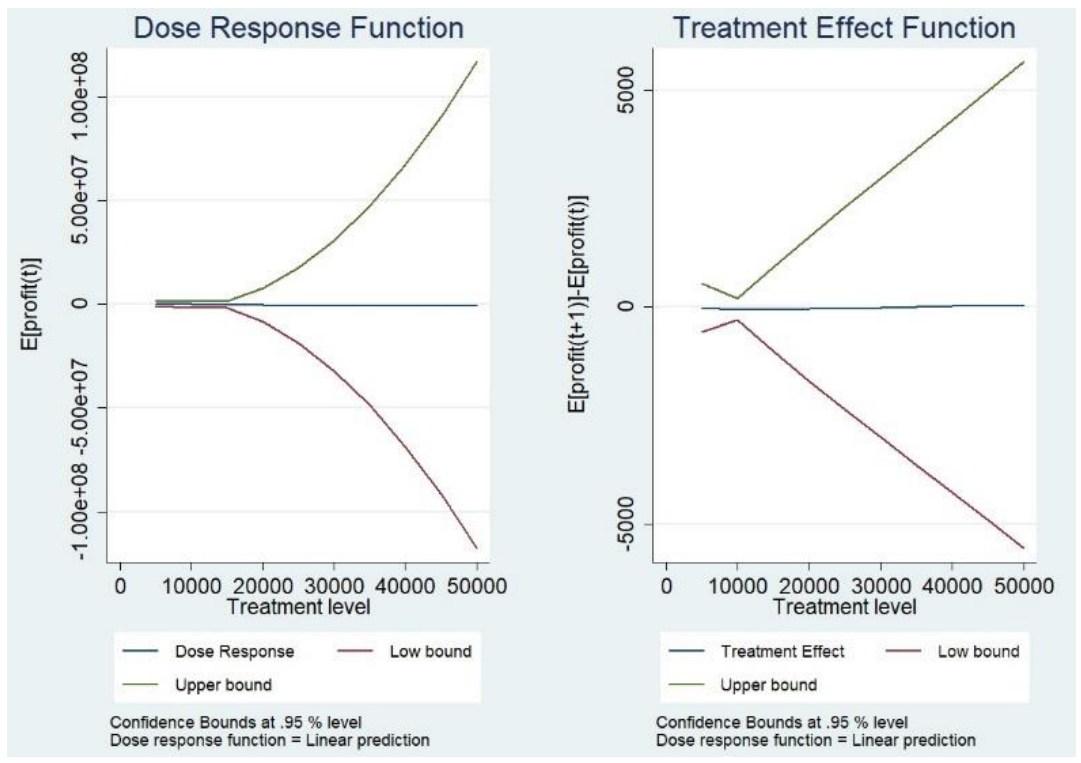

Source: author's elaboration

Figure 3 and Table 4 show the differentiated impact of R\&D support on firms' labour productivity in various size categories. The dose-response and treatment effect functions have convex curvatures for small and large firms. Also, for both groups, it holds that productivity effects are largely negative (except in small firms with the support of over CZK 17 million). On the other hand, marginal effects grow with the support over CZK 5 million and CZK 10 million respectively). For the group of medium-size firms, the estimated doseresponse function is positive. However, the marginal treatment effects increase with the support until it reaches CZK 5 million (a point of saturation), and then decrease thereafter with higher levels of $R \& D$ support received by a medium sized firm. 
Figure 3 | Dose-response functions of labour productivity

\section{Small firms}

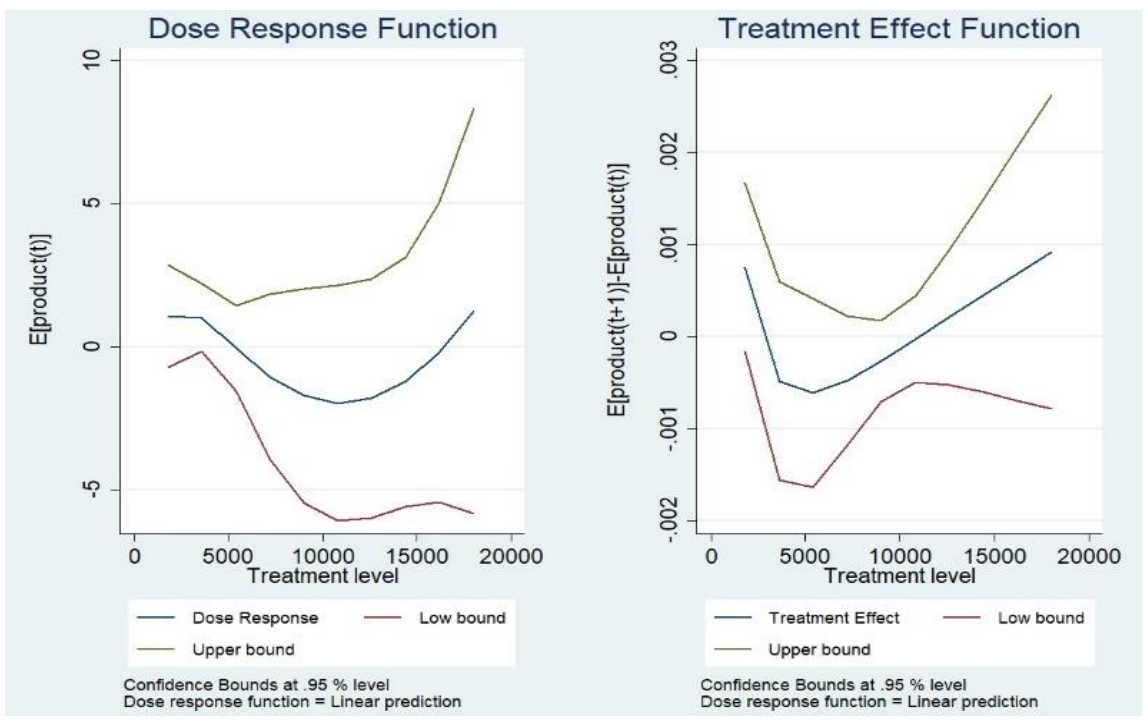

Source: author's elaboration

\section{Medium firms}

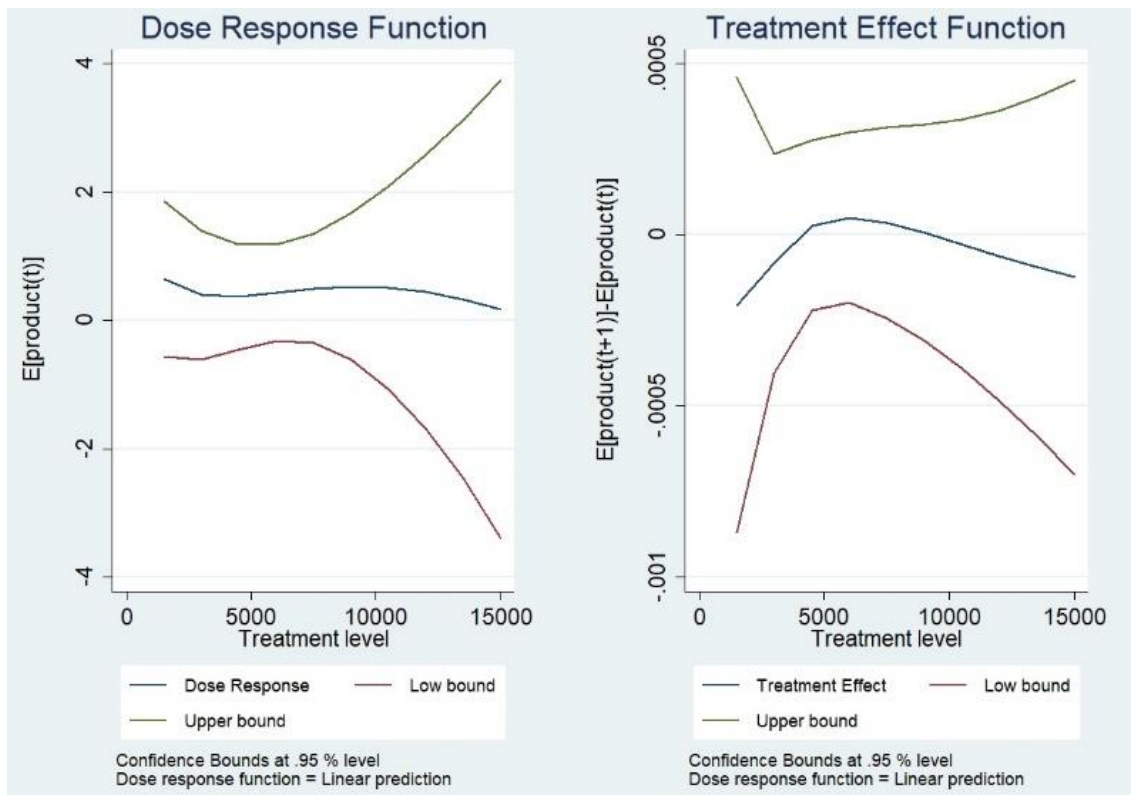

Source: author's elaboration 


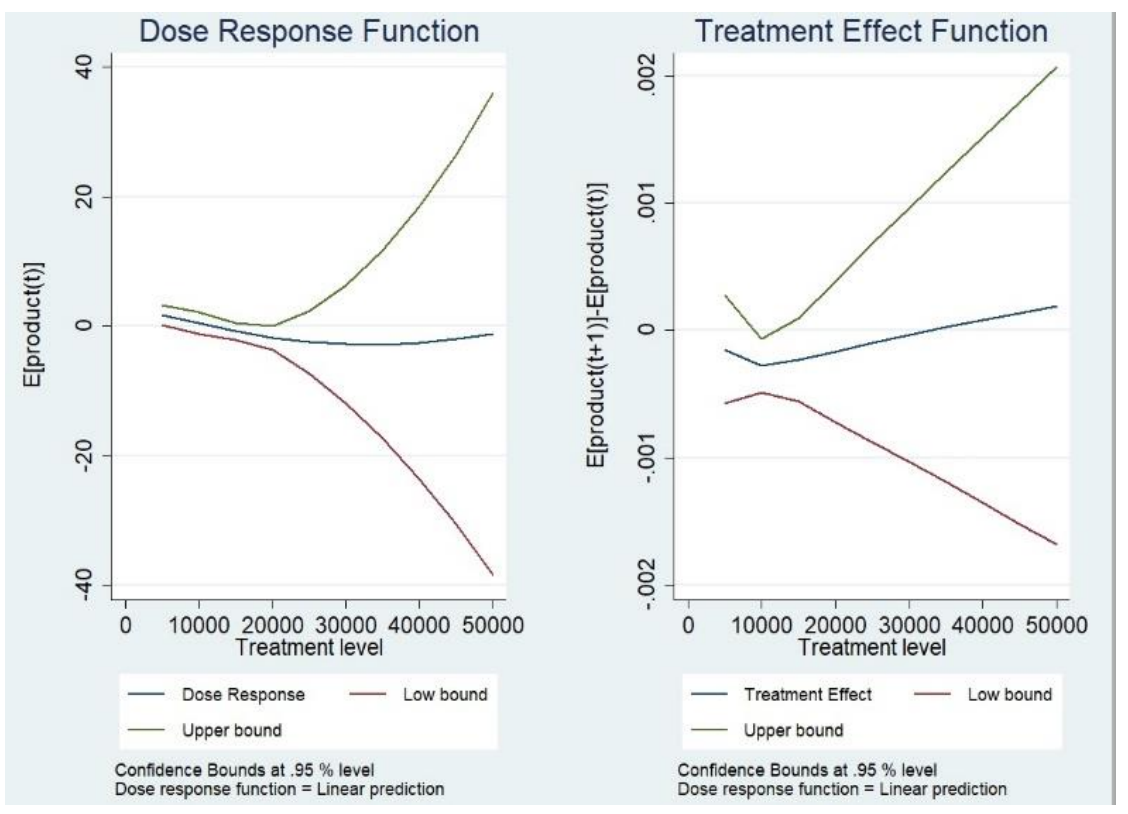

Source: author's elaboration

Table 4 | Review of effect of the R\&D support on labour productivity

\begin{tabular}{|c|c|c|c|}
\hline Size group & Function & Shape & Interpretation \\
\hline \multirow[t]{2}{*}{ Small } & Dose-response & Concave & $\begin{array}{l}\text { Largely negative, positive effects when } \\
\text { supports }>17 \text { mil. CZK }\end{array}$ \\
\hline & Treatment effect & Concave & $\begin{array}{l}\text { Increasing marginal effects when } \\
\text { supports bigger than } 5 \text { mil. CZK }\end{array}$ \\
\hline \multirow[t]{2}{*}{ Medium } & Dose-response & Flat S-shape & Positive effects \\
\hline & Treatment effect & Concave & $\begin{array}{l}\text { Increasing marginal effect up to } 5 \text { million } \\
\mathrm{CZK} \text {, then declining }\end{array}$ \\
\hline \multirow[t]{2}{*}{ Large } & Dose-response & Concave & Small negative effects \\
\hline & Treatment effect & Concave & $\begin{array}{l}\text { Increasing marginal effects when the } \\
\text { support exceeds CZK } 13 \text { million. }\end{array}$ \\
\hline
\end{tabular}

Note: the support figures are per the investigated support period.

Source: own interpretation

These findings broadly support results and conclusions of other studies mentioned above on heterogeneous effects of the R\&D support on various size categories of firms. Consistent with the literature (e.g. Pavitt et al., 1987; Acs \& Audretsch, 1988; Rothwell \& Dodgson, 1994), we found the positive effects of the subsidy on SMEs. Besides, our findings for these firms seem to be consistent with those of Nunes et al. (2012) who showed that relationships between R\&D support and economic performance of these companies were not linear. Instead, they found an inverted U-shape relationship between R\&D intensity and high-tech SMEs growth and concluded that R\&D intensity restricts the growth of high-tech SMEs at 
lower levels whist improving growth at higher levels of R\&D investments. As for the effects on productivity, our results support previous research of Vanino et al. (2019) who found substantial impacts of R\&D support on the productivity of small and least productive firms relative to large firms. However, the authors argue that the impact was substantial in six years after the programme implementation. This could explain why the observed effects on large companies were neutral or slightly negative.

\section{Conclusions}

The results confirm the earlier assumption that treatment effects differ depending on firm sizes (categories). It shows that in the relatively short period, the evaluated program was generally more beneficial to small and medium enterprises than to large firms. It also shows that the program impacts positively on the output (profit, productivity and GVA) of small firms only if they received more than a certain amount of the support (a support threshold) whereas effects diminish for medium firms beyond a point of saturation. The differences in impacts between the size categories of supported enterprises can be explained by the different economic performance of small firms compared to the medium and large companies and different strategic focus of R\&D in each size category. Small companies are more likely to concentrate on activities with a faster return on capital. Therefore, R\&D conducted by small firms is rather oriented on the direct support of their production activities or the application of the new knowledge in the short-term horizon, while the strategic focus of R\&D in large companies are more focused on long-term strategic research.

In line with Bondonio et al. (2016), we can stress that investigating effects of the subsidies to economic performance depend on the fact that the investment in $R \& D$ requires more time to mature and to provide noticeable impacts on general firm-level performance. Besides, a qualitative survey carried out as part of the TIP program evaluation (Čadil et al., 2018) showed that the transfer of R\&D outputs into commercially used real innovation took several years, depending on the technological progress, production capacity of the company and the development of market demand.

Our findings have some policy implications, namely for the policy design and the evaluation. Firstly, the heterogeneity of the effects on various scale categories should be considered when setting the objectives of policies and programs in particular. While for small and medium companies the desired effects (and thus goals) may occur in the short term, for large companies it may be in the medium to long term. Similarly, this effect for individual size categories of enterprises may depend on the volume of the R\&D support received. Therefore, it is important to determine the thresholds for R\&D support effectiveness. Finally, the achievement of the program objectives and economic effects should not be evaluated together for all size categories of enterprises, especially when using advanced quantitative methods, but the specifics of individual size categories should be considered in the evaluation exercise.

Taking into account that GPSM approach is demanding in terms of investigator's skill and investigation time it is rather questionable to pursue the application of the advanced methods if there is little expectation that the effects can occur, especially if these effects occur in several years after the program completion. On the other hand, we can confirm that GPSM approach provides logical outcomes and if the investigation is situated to the right time after 
the program is accomplished it has potential to bring more insight in the effects than the standard dichotomous model.

High variance and heterogeneity of the effect variables limit the practical usefulness of the results. It is at least partly due to missing information on the other public support provided to the investigated firms and of course due to market differences and fluctuations of sales. Note, that this problem will be similarly severe when using standard propensity score matching (PSM) method. Thus, any further research should make attempt to control for these factors. First of all, it will be useful to consider (and to get data) the other programs/measures of similar objectives. In addition, one should think about the split of the sample in more homogenous groups than are the size groups. Specialization, labour or capital intensity might be such characteristics to be considered when setting up the "homogenous" groups.

\section{References}

Acs, Z., \& Audretsch, D. (1988). Innovation in large and small firms: An empirical analysis. American Economic Review, 78(4), 678-690.

Audretsch, D., \& Vivarelli, M. (1996). Firms size and R\&D spillovers: Evidence from Italy. Small Business Economics, 8(3), 249-258. https://doi.org/10.1007/BF00388651

Autio, E., \& Rannikko, H. (2016). Retaining winners: Can policy boost high-growth entrepreneurship? Research Policy, 45(1), 42-55. https://doi.org/10.1016/j.respol.2015.06.002

Becker, B. (2015). Public R\&D policies and private R\&D investment: A survey of the empirical evidence. Journal of Economic Surveys, 29(5), 917-942. https://doi.org/10.1111/joes.12074

Bia, M., \& Mattei, A. (2012). Assessing the effect of the amount of financial aids to Piedmont firms using the generalized propensity score. Statistical Methods \& Applications, 21, 485-516. https://doi.org/10.1007/s10260-012-0193-4

Bondonio, D., Biagi, F., \& Stancik, J. (2016). Counterfactual Impact Evaluation of Public Funding of Innovation, Investment and $R \& D$ [online]. https://doi.org/10.2791/240240

Bozeman, B., \& Deitz, J.S. (2001). Research policy trends in the United States. In P. Laredo \&, P. Muster (Eds.). Research and innovation policy in the new global economy, and international comparative analysis (pp. 47-78). Cheltenham, UK: Edward Elgar.

Bronzini, R., \& Piselli, P. (2016). The impact of R\&D subsidies on firms innovation. Research Policy, 45(2), 442-457.

Cunningham, P., Gök, A., \& Larédo, P. (2016). The impact of direct support to R\&D and innovation in firms. In J. Edler, P. Cunningham, A. Gök \& P. Shapira (Eds.). Handbook of innovation policy impact (pp. 54-107). Cheltenham, UK: Edward Elgar.

Cunningham, P., den Hertog, P., \& Peter, V. (2017). Ex-post evaluation of business R\&I grant schemes. Expert panel report prepared for the Horizon 2020 Policy Support Facility, Mutual Learning Exercise, Brussels, European Commission.

Czarnitzki, D., \& Delanote, J. (2015). R\&D policies for young SMEs: Input and output effects. Small Business Economics, 45(3), 465-485. https://doi.org/10.1007/s11187-015-9661-1

Čadil, V., Kučera, Z., Vondrák, T., \& Pecha, O. (2018). Závěrečné hodnocení programu na podporu aplikovaného výzkumu, experimentálního vývoje a inovací TIP. Technologické centrum AV ČR. 
Dvouletý, O., Srhoj, S., \& Pantea, S. (2020). Public SME grants and firm performance in European Union: A systematic review of empirical evidence. Small Business Economics (2020). https://doi.org/10.1007/s11187-019-00306-x

Grilli, L., \& Murtinu, S. (2012). Do public subsidies affect the performance of new technology-based firms? The importance of evaluation schemes and agency goals. Prometheus, 30(1), 97-111. https://doi.org/10.1080/08109028.2012.676836

Herrera, L., \& Sanchez-Gonzalez, G. (2013). Firm size and innovation policy. International Small Business Journal, 31(2), 137-155. https://doi.org/10.1177/0266242611405553

Hirano, K., \& Imbens, G.W. (2004). The propensity score with continuous treatments. In A. Gelman \& XL. Meng (Eds.). Applied Bayesian modeling and causal inference from incomplete-data perspectives (pp. 73-84). Hoboken, NJ: John Wiley \& Sons.

Hong, J., Wang, L., Xu, Y., \& Zhao, D. (2015). Governments grants, private R\&D funding and innovation efficiency in transition economy. Technology Analysis \& Strategic Management, 27(9), 1068-1096. https://doi.org/10.1080/09537325.2015.1060310

Horák, P., \& Květoň, V. (2019). The effect of public R\&D subsidies on firm's competitiveness: Regional and sectoral specifics in emerging innovation systems. Applied Geography, 94(May), 119-129. 10.1016/j.apgeog.2018.03.015

Huergo, E., \& Moreno Martín, L. (2017). Subsidies or loans? Evaluation the impact of R\&D support programmes. Research Policy, 46(7), 1198-1214. https://doi.org/10.1016/j.respol.2017.05.006

Karhunen, H., \& Huovari, J. (2015). The impact of R\&D subsidies during the crisis. Small Business Economics, 45(4), 805-823. https://doi.org/10.1007/s11187-015-9658-9

Khandker, S.R., Koowal, G.B., \& Samad, A.H. (2010). Handbook on impact evaluation: Quantitative methods and practices. Washington, DC: World Bank.

Nunes, M.P., Serrasqueiro, Z., \& Leitão, J. (2012). Is there a linear relationship between R\&D intensity and growth? Empirical evidence of non-high-tech vs. high-tech SMEs. Research Policy, 41(1), 36-53. https://doi.org/10.1016/j.respol.2011.08.011

Pavitt, K., Robson, M., \& Townsend, J. (1987). The size distribution of innovating firms in the UK: 19451983. The Journal of Industrial Economics, 35(3), 297-316. https://doi.org/10.2307/2098636

Petrin, T. (2017). A literature review on the impact and effectiveness of government support for R\&D and innovation [working paper no. 05/2018, online]. Retrieved from http://www.isigrowth.eu/wpcontent/uploads/2018/02/working_paper_2018_05.pdf

Radicic, D., Pugh, G., Hollanders, H. et al. (2016). The impact of innovation support programmes on small and medium enterprises innovation in traditional manufacturing industries: An evaluation for seven European Union regions. Environment and Planning C: Policies and Space, 34(8), 1425-1452. https://doi.org/10.1177/0263774X15621759

Radicic, D., \& Pugh, G. (2015). Input and output additionality of R\&D programmes in European SMEs. Proceedings of the European Conference on Entrepreneurship and Innovation (ECIE 2015), 567-575.

Ratinger, T., Čadil, V., \& Agyemang Amaoko, S. (2019). Are there any economic impacts of business R\&D support? The case of the Czech Republic. In O. Dvouletý, M. Lukeš, \& J. Mísař (Eds.). Innovation Management, Entrepreneurship and Sustainability. Proceedings of the 7th International Conference (pp. 771-782). Prague University of Economics and Business.

Raymond, L., \& St-Pierre, J. (2010). R\&D as a determinant of innovation in manufacturing SMEs: An $\begin{array}{llll}\text { attempt at empirical } & \text { clarification. } & \text { Technovation, } & \text { 48-56. }\end{array}$ https://doi.org/10.1016/j.technovation.2009.05.005 
Rosenbaum, P.R., \& Rubin, D.B. (1983). The central role of the propensity score in observational studies for causal effects. Biometrika, 70(1), 41-55. https://doi.org/10.1093/biomet/70.1.41

Rothwell, M., \& Dodgson, R. (1994). The handbook of industrial innovation. Cheltenham, UK: Edward Elgar.

Sidorkin, O., \& Srholec, M. (2017). Do direct subsidies stimulate new R\&D outputs in firms? A comparison of the IMPULS, TIP and ALFA programmes [online]. Retrieved from https://idea.cergeei.cz/files/IDEA_Study_8_2017_Direct_subsidies_and_R\&D_output_in_firms.pdf

Stam, E., \& Wennberg, A.K. (2009). The roles of R\&D in new firm growth. Small Business Economics, 33, 77-89. https://doi.org/10.1007/s11187-009-9183-9

Špička, J. (2018). How do agricultural biogas investments affect Czech farms? Central European Business Review, 7(1), 34-60. https://doi.org/10.18267/j.cebr.205

Vanino, E., Roper, S., \& Becker, B. (2019). Knowledge to money: Assessing the business performance effects of publicly-funded R\&D grants. Research Policy, 48(7), 1714-1737. https://doi.org/10.1016/j.respol.2019.04.001

Testa, G., Szkuta, K., \& Cunningham, P.N. (2019). Improving access to finance for young innovative enterprises with growth potential: Evidence of the impact of R\&D grant schemes on firms' outputs. Research Evaluation, 28(4), 355-369

What Works Centre for Local Economic Growth (2015). Innovation: Grants, Subsidies and Loans. Evidence Review 9 [online]. Retrieved from https://whatworksgrowth.org/public/files/Policy_Reviews/1510-20-Innovation-Grants-Loans-Subsidies-Report.pdf

Zemplinerová, A., \& Hromádková, E. (2012). Determinants of firm's innovation. Prague Economic Papers, 21(4), 487-503. https://doi.org/10.18267/j.pep.436

Zúñiga-Vicente, J.Á., Alonso-Borrego, C., Forcadell, F.J., \& Galán, J.I. (2014). Assessing the effect of public subsidies on firm R\&D investment: A survey. Journal of Economic Surveys, 28(1), 36-67. https://doi.org/10.1111/j.1467-6419.2012.00738.x

The research paper passed the review process. | Received: May 29, 2020; Revised: July 3, 2020; Accepted: July 8, 2020; Published: December 21, 2020 